\title{
Study of Lipid Profile in Different grades of Non- Alcoholic Fatty Liver Disease
} Farag Khalil, Mohamed Nabil Rafat, Mohamed Salah, Mamdouh Attia Mohamed, Wafeek Ibrahim* Internal Medicine Department, *Radiology department, Faculty of Medicine Al-Azhar University Cairo Egypt. Corresponding Author: Farag Khalil, Email: dr.farag7070@azhar.edu.eg

\begin{abstract}
Background: The prevalence of NAFLD (non- alcoholic fatty liver disease) is increasing as it exceed (31.79\%) in Middle East and the metabolic syndrome prevalence in patients with NAFLD ranges from 18\% to 67\%, according to the body weight. Imaging or histology is very important tools in diagnosis of NAFLD. Early detection of NAFLD is very important especially if there is a non-invasive method. The clinicians in the primary, secondary and tertiary care are in need for specific and sensitive diagnostic tool that can be used easily.

Aim: To study and analyze serum lipid changes in non-alcoholic fatty liver disease of different grades.

Patients and methods: 100 patients diagnosed by ultrasonography as NAFLD, whose age was more than 18 years, were included in the study. History taking, full clinical examination and anthropometric measurement of weight, height and body mass index (BMI) were done for all patients. Serum lipid profiles including total cholesterol, HDL, LDL, triglycerides, ALT, AST. CBC, fasting and 2hpp blood glucose and TSH were measured.

Results: The largest group of patients (38\%) was in the fifth decade of life. followed by $30 \%$ in the sixth decade of life. As the grade of NAFLD increased, there was associated significant increase in levels of serum total cholesterol (P-value 0.005), TG (P-value 0.002) LDL (P-value 0.001) and VLDL (P-value 0.003) and associated significant decrease in HDL (P-value 0.001).
\end{abstract}

Conclusions: abdominal ultrasonography and increased lipid profile values can be used to detect NAFLD early. Key words: NAFLD, Lipid Profile, Ultrasonographic grading of NAFLD

\section{INTRODUCTION}

NAFLD in developed countries is the most prevalent chronic liver disease. The Middle East has reported the highest prevalence of NAFLD (31.79\%) and South America $(30.45 \%)$ but Africa has the lowest prevalence rate $(13.48 \%)^{(\mathbf{1})}$.

NAFLD develops due to abnormal triglycerides accumulation in the liver cells, leading to histologically benign disease named simple steatosis but it can progress to histologically aggressive form characterized by inflammation and liver cell injury with or without fibrosis called steatohepatitis $(\mathrm{NASH}){ }^{(2)}$.

Non-alcoholic fatty liver disease diagnosis needs (1) exclusion of history of heavy alcohol consumption and steatogenic drug use (2) detection of steatosis by histology or imaging ${ }^{(3)}$.

By definition, NAFLD is the presence of more than 5\% hepatic steatosis in the absence of hepatocellular injury but in NASH there is more than $5 \%$ hepatic steatosis with presence of inflammation and hepatocellular injury with or without fibrosis ${ }^{(3)}$.

Visceral obesity, dyslipidemia, type 2 diabetes mellitus and metabolic syndrome are the most important risk factors for NAFLD. In lipid metabolism, thyroid hormones play an essential role. Hypercholesterolemia caused by decreased thyroid hormone levels has a fundamental role in the development of NAFLD ${ }^{(4)}$.

NAFLD and cardiovascular diseases share the similar risk factors. The mortality and morbidity of cardiovascular disease are increased in the presence of NAFLD ${ }^{(5)}$.

Most NAFLD cases have a benign course without symptoms or signs of liver disease but some cases can be progressive and develop fibrosis and cirrhosis or even liver failure and hepatocellular carcinoma ${ }^{(\mathbf{6}}$.

Ultrasound can detect the liver fatty infiltration but cannot differentiate between NAFLD and NASH. This differentiation needs a liver biopsy and is essential because of the much higher risk of liver fibrosis and cirrhosis with NASH than NAFLD. However, liver biopsy is clinically impractical because of the large numbers of patients with NAFLD and that most patients are asymptomatic and its high cost and sampling errors ${ }^{(7)}$. Also it is a painful procedure with dangerous complication like bleeding ${ }^{(8)}$.

The ultrasound has moderate accuracy and is widely available so it is the primary tool to diagnose NAFLD in routine practice ${ }^{(9)}$.

\section{PATIENTS AND METHODS}

This is a cross sectional prospective study. Total 100 patients older than 18 years were enrolled in this study. They were diagnosed by ultrasound as nonalcoholic fatty liver disease. An informed consent was taken from all patients. The American Gastroenterology Association criteria were used for classification of the patients ${ }^{(\mathbf{1 0})}$.

All the ultrasound examinations were performed on Voluson E6 US Scanners using 3-5 MHz. 
NAFLD Grades by ultrasound

Grade (I) mild increase in the liver echogenicity. The diaphragm and intrahepatic blood vessel are normally visualized. Grade (II) moderate increase in echogenicity of the liver obscuring periportal echogenicity but the diaphragm is still visualized. Grade (III) severe increase in the liver echogenicity. Both the intrahepatic blood vessel and diaphragm are poorly visualized.

History taking and full clinical examination were done for all patients. The weight, height and body mass index (BMI) were measured for all participants. Overweight was calculated as BMI between 25 and $30 \mathrm{~kg} / \mathrm{m}^{2}$. Obesity was calculated as BMI more than $30 \mathrm{~kg} / \mathrm{m}^{2}$.

Serum triglycerides, total cholesterol, high density lipoprotein, low density lipoprotein, very low density lipoprotein, ALT, AST, were measured for all patients and were compared in different grades of these patients. Complete blood picture, fasting and 2hpp blood glucose, TSH were done for all patients. Exclusion criteria:

1- Patients with heavy alcohol intake (more than 20 gram per day).

2- Other diseases that may cause the liver condition such as chronic hepatitis C and B and HIV.

3- Hypothyroidism.

\section{Statistical methods}

Data were entered in the SPSS version 16 for windows and was analyzed. Frequency, Mean values, standard deviations were calculated for individual variables. Analysis of different grade of NAFLD with variable component of lipid profile was done using analysis of variance (ANOVA) test. $\mathrm{P}$ value was calculated and value less than 0.05 was considered significant.

\section{RESULTS}

Our study was conducted on 100 patients diagnosed by ultrasound as non-alcoholic fatty liver disease. Out of them $58 \%$ were males and $42 \%$ were females.

Table (1): Demographic data of the studied groups

\begin{tabular}{|c|c|c|}
\hline Age distribution & $\begin{array}{l}\text { NO. of subjects } \\
(\mathrm{n}=100)\end{array}$ & $\begin{array}{l}\text { Percentage } \\
(\%)\end{array}$ \\
\hline $20-29$ & 3 & $3 \%$ \\
\hline $30-39$ & 19 & $19 \%$ \\
\hline $40-49$ & 38 & $38 \%$ \\
\hline $50-59$ & 30 & $30 \%$ \\
\hline 60 and above & 10 & $10 \%$ \\
\hline Total & 100 & $100 \%$ \\
\hline
\end{tabular}

The largest proportion of our patients (38\%) were between 40 and 49 years, $30 \%$ of our patients were between 50 and 59 years, $19 \%$ between 30 to 39 years, $10 \%$ were 60 year and above and $3 \%$ between 20 to 29 year.

The mean age of the participants \pm SD was 47.25 \pm 8.98 . The Minimum age was 27 years and the maximum age was 66 years. The largest groups of patient were in the fifth and sixth decades.

Table (2): Age distribution of the studied group

\begin{tabular}{|l|c|c|c|c|c|}
\hline \hline Age group & Grade 1 (51) & Grade 2 (42) & Grade 3 (7) & & P-value \\
\hline \hline $20-29$ & $3(5.9)$ & $0(0.0)$ & $0(0.0)$ & \multirow{2}{*}{ Fischer exact= } & \multirow{2}{*}{38.33} \\
\hline $30-39$ & $16(31.4)$ & $3(7.1)$ & $0(0.0)$ & \\
\hline $40-49$ & $24(47.1)$ & $14(33.3)$ & $0(0.0)$ & & \\
\hline $50-59$ & $8(15.7)$ & $19(45.2)$ & $3(42.9)$ & & \\
\hline 60 and above & $0(0.0)$ & $6(14.3)$ & $4(57.1)$ & & \\
\hline \hline
\end{tabular}

Our study had showed statistically significant correlation of age with grades of NAFLD (p-value 0.001).

Table (3): BMI classification among the studied groups

\begin{tabular}{|c|c|c|}
\hline Items & \multicolumn{2}{|c|}{$\mathrm{N}=100$} \\
\hline BMI in $\mathrm{kg} / \mathrm{m}^{2}:($ Mean \pm SD $)$ & \multicolumn{2}{|c|}{$29.87 \pm 4.63$} \\
\hline BMI Classification: & NO. & $\%$ \\
\hline Normal & 19 & $19.0 \%$ \\
\hline Overweight & 31 & $31.0 \%$ \\
\hline Obese & 50 & $50.0 \%$ \\
\hline
\end{tabular}

BMI of the participants varied from 22.5 to $42.1 \mathrm{~kg} / \mathrm{m}^{2}$ with mean value of $29.87 \pm 4.63 \mathrm{~kg} / \mathrm{m}^{2} .19 \%$ of the studied group had normal BMI, $31 \%$ were overweight and $50 \%$ were obese. 
Table (4): BMI classification in grades of NAFLD

\begin{tabular}{|c|c|c|c|c|c|c|}
\hline \multirow[b]{2}{*}{ BMI classification } & & \multicolumn{3}{|c|}{ Grade } & \multirow[b]{2}{*}{ Chi- } & \multirow[t]{2}{*}{$\mathrm{p}$-value } \\
\hline & & Grade 1 & Grade 2 & Grade 3 & & \\
\hline Normal & Count & 12 & 6 & 1 & \multirow{8}{*}{7.326} & \multirow{8}{*}{0.120} \\
\hline & $\%$ within grade & $23.5 \%$ & $14.3 \%$ & $14.3 \%$ & & \\
\hline overweight & Count & 14 & 12 & 5 & & \\
\hline & $\%$ within grade & $27.5 \%$ & $28.6 \%$ & $71.4 \%$ & & \\
\hline Obese & Count & 25 & 24 & 1 & & \\
\hline & $\%$ within grade & $49.0 \%$ & $57.1 \%$ & $14.3 \%$ & & \\
\hline Total & Count & 51 & 42 & 7 & & \\
\hline & $\%$ within grade & $100.0 \%$ & $100.0 \%$ & $100.0 \%$ & & \\
\hline
\end{tabular}

In our study no association was found between grades of NAFLD and BMI P-value is 0.120 .

Table (5): Sex distribution among the studied groups

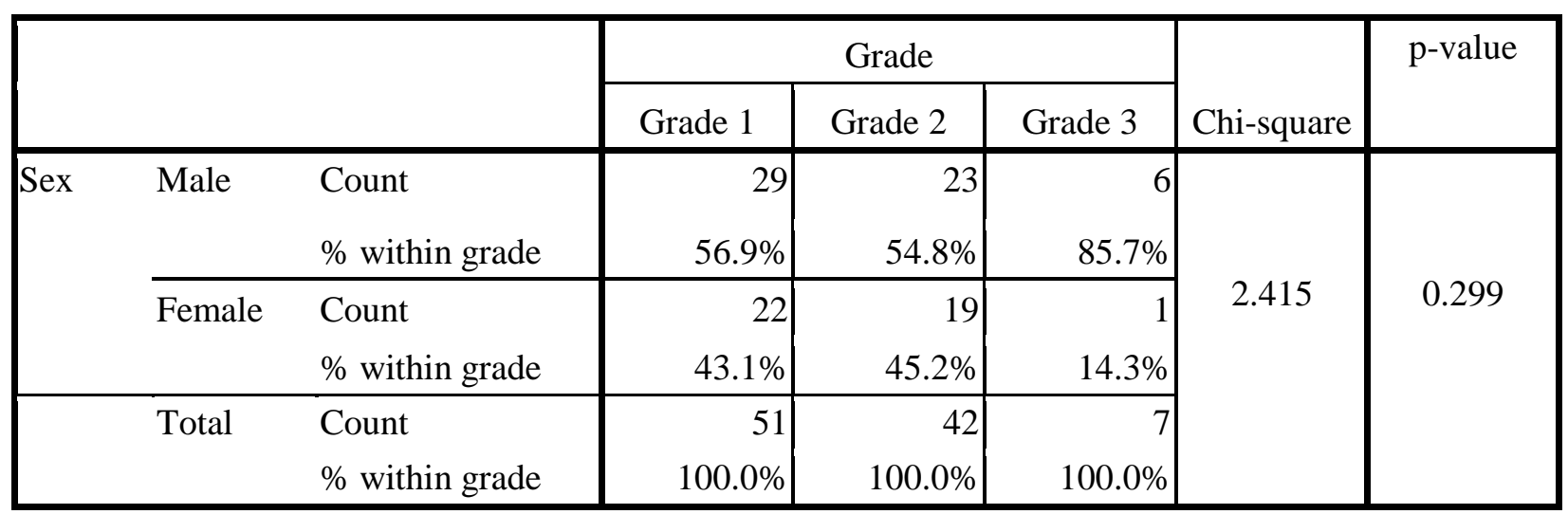

In our study no association was found between grades of NAFLD and sex P-values is 0.299.

Table (6): DM and HTN classification among the studied groups

\begin{tabular}{|ll|c|c|c|}
\hline \multirow{2}{*}{} & \multicolumn{2}{|c|}{ D.M } & \multirow{2}{*}{ Total } \\
\cline { 2 - 4 } & hypertensive & Diabetic & not diabetic & 18 \\
& & 7 & 11 & 82 \\
TTN & 30 & 52 & 100 \\
\hline
\end{tabular}

Out of 100 subjects included in the study $37 \%$ were diabetic, $18 \%$ were hypertensive and $7 \%$ were both diabetic and hypertensive. 
Figure (5): Grades of NAFLD among the studied group

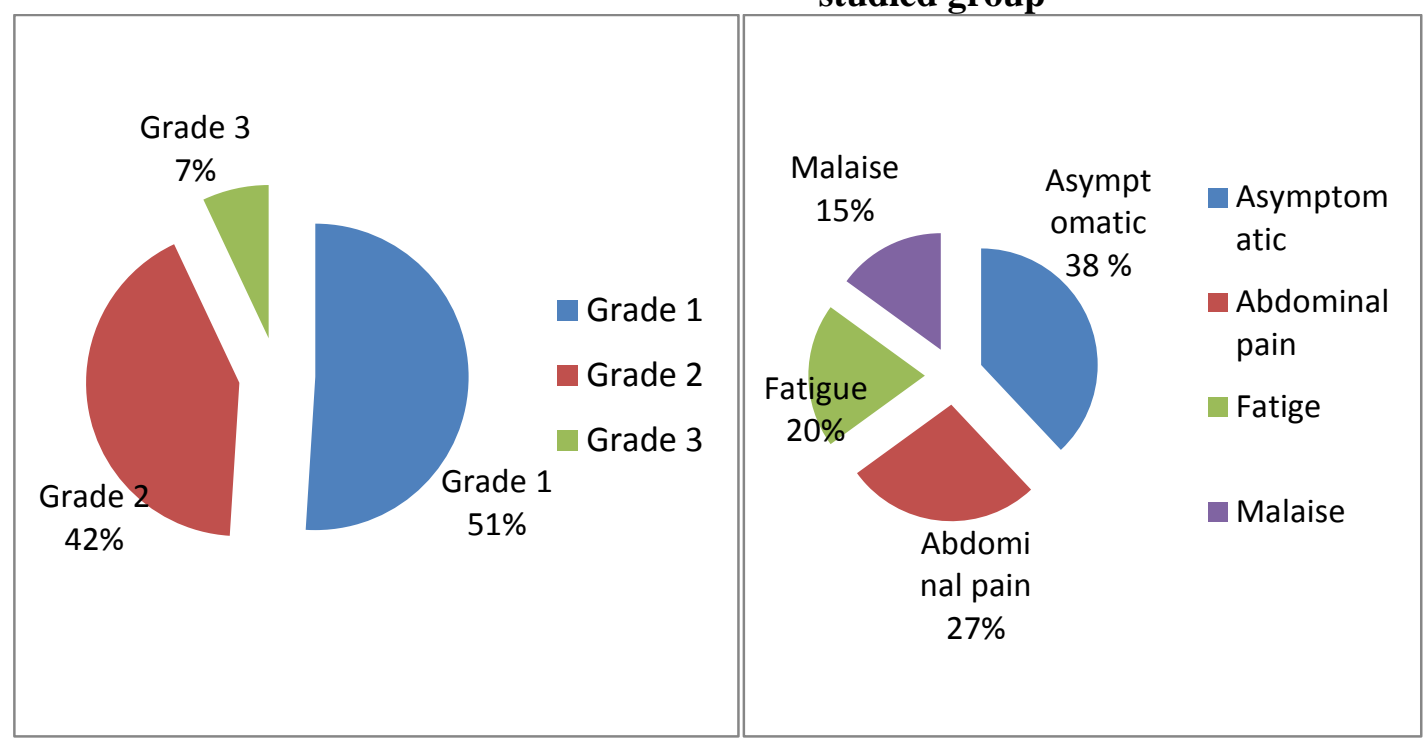

Out of 100 subjects included in the study $51 \%$ were grade I, $42 \%$ were grade II and $7 \%$ were grade III.

Out of 100 subjects included in the study $38 \%$ were asymptomatic, $27 \%$ complained of abdominal pain or discomfort, $20 \%$ complained of fatigue and $15 \%$ complained of malaise.

Table (9): liver enzymes in different grades of NAFLD

\begin{tabular}{|c|c|c|c|c|c|c|}
\hline \multirow{2}{*}{\multicolumn{2}{|c|}{ Liver enzymes }} & \multicolumn{3}{|c|}{ Grade } & \multirow[t]{2}{*}{ Chi-square } & \multirow{2}{*}{$\mathrm{p}$-value } \\
\hline & & Grade 1 & Grade 2 & Grade 3 & & \\
\hline Normal & $\begin{array}{l}\text { Count } \\
\% \text { within grade }\end{array}$ & $\begin{array}{c}47 \\
92.16 \%\end{array}$ & $\begin{array}{c}29 \\
69.05 \%\end{array}$ & $\begin{array}{c}3 \\
42.86 \%\end{array}$ & \multirow[b]{3}{*}{13.341} & \multirow[b]{3}{*}{0.001} \\
\hline Elevated & $\begin{array}{l}\text { Count } \\
\% \text { within grade }\end{array}$ & $\begin{array}{c}4 \\
7.84 \%\end{array}$ & $\begin{array}{c}13 \\
30.95 \%\end{array}$ & $\begin{array}{c}4 \\
57.14 \%\end{array}$ & & \\
\hline Total & $\begin{array}{l}\text { Count } \\
\% \text { within grade }\end{array}$ & $\begin{array}{c}51 \\
100.0 \%\end{array}$ & $\begin{array}{c}42 \\
100.0 \%\end{array}$ & $\begin{array}{c}7 \\
100.0 \%\end{array}$ & & \\
\hline
\end{tabular}

Table (10): Comparison between NAFLD grades and the lipid profile

\begin{tabular}{|c|c|c|c|c|c|c|c|}
\hline \multirow[b]{2}{*}{ Items } & \multicolumn{3}{|c|}{ Grade } & \multirow{2}{*}{$\begin{array}{c}\text { Test of } \\
\text { significance } \\
\text { ANOVA }\end{array}$} & \multicolumn{3}{|c|}{ P value } \\
\hline & $\begin{array}{c}\text { Grade } 1 \\
(\mathrm{~N}=51)\end{array}$ & $\begin{array}{c}\text { Grade } 2 \\
(\mathrm{~N}=42)\end{array}$ & $\begin{array}{c}\text { Grade } 3 \\
(N=7)\end{array}$ & & $\begin{array}{l}\text { G1- } \\
\text { G2 }\end{array}$ & G1-G3 & G2-G3 \\
\hline $\begin{array}{l}\text { T. Cholesterol in } \\
(\mathrm{mg} / \mathrm{dl}): \\
(\mathrm{Mean} \pm \mathrm{SD})\end{array}$ & $202.55 \pm 46.49$ & $232.4 \pm 44.16$ & $233.0 \pm 33.41$ & $\begin{array}{c}\mathrm{F}=5.579 \\
\mathrm{p} \text { value }=0.005\end{array}$ & $\begin{array}{c}0.000 \\
*\end{array}$ & "0.008* & 1.0 \\
\hline $\begin{array}{l}\text { TG in }(\mathrm{mg} / \mathrm{dl}) \text { : } \\
(\text { Mean } \pm \text { SD) }\end{array}$ & $168.98 \pm 46.03$ & $202.57 \pm 59.4$ & $226.71 \pm 50.66$ & $\begin{array}{c}\mathrm{F}=6.888 \\
\mathrm{p} \text { valu }=0.002\end{array}$ & $\begin{array}{c}0.000 \\
*\end{array}$ & $0.001 *$ & 0.29 \\
\hline $\begin{array}{l}\text { HDL(U/L ): } \\
(\text { Mean } \pm \text { SD) }\end{array}$ & $50.17 \pm 8.73$ & $44.43 \pm 8.72$ & $39.85 \pm 5.98$ & $\begin{array}{c}\mathrm{F}=7.795 \\
\mathrm{p} \text { value }=0.001\end{array}$ & $\begin{array}{c}0.001 \\
*\end{array}$ & $0.002 *$ & 0.36 \\
\hline $\begin{array}{l}\text { LDL(U/L ): } \\
(\text { Mean } \pm \text { SD) }\end{array}$ & $125.15 \pm 27.65$ & $148.78 \pm 31.29$ & $146.71 \pm 31.1$ & $\begin{array}{c}\mathrm{F}=7.852 \\
\mathrm{p} \text { value } 0.001\end{array}$ & $\begin{array}{c}0.000 \\
*\end{array}$ & 0.056 & 1.0 \\
\hline $\begin{array}{l}\text { VLDL(U/L ): } \\
(\text { Mean } \pm \text { SD) }\end{array}$ & $28.49 \pm 7.54$ & $34.83 \pm 11.01$ & $35.85 \pm 9.61$ & $\begin{array}{c}\mathrm{F}=6.133 \\
0.003\end{array}$ & $\begin{array}{c}0.000 \\
*\end{array}$ & $0.022 *$ & 1.0 \\
\hline
\end{tabular}

The liver enzymes were elevated in $\mathbf{2 1 \%}$ of the studied group. Our study had showed statistically significant correlation of enzyme elevation with grades of NAFLD (p-value 0.001 ). 
The Analysis of Variance Test (ANOVA) was used to compare lipid changes in NAFLD grades and it was considered significant if the $\mathrm{P}$ values less than 0.05. It was noted that as the grade of NAFLD increased, there were associated significant increase in levels of serum total cholesterol (P-value 0.005), TG (P-value 0.002), LDL (P-value 0.001) and VLDL (P-value 0.003 ) and associated significant decrease in HDL (P-value 0.001).

Results of Bonferroni corrected post-hoc t-tests for each group of the three data sets. The Bonferroni corrected p-value is $<0.05$ between grade 1 and (grade2,3) for total cholesterol, TG, and HDL .

\section{DISCUSSION}

Our study was conducted on 100 patients diagnosed by ultrasound as non-alcoholic fatty liver disease. The American Gastroenterology Association criteria were used for classification of the patients ${ }^{(\mathbf{1 0})}$.

In the present study males are predominant as compared with females; 58 males (58\%) and 42 females (42\%). In a study by Tanwani et al., majority of participants $203(67.7 \%)$ were males and females were $97(32.3 \%)^{(11)}$. In another study by Bhusal et al., males were $67 \%$ and females were $33 \%{ }^{(10)}$.

The mean age of the participants \pm and SD was $47.25 \pm 8.98$. The minimum age was 27 years and the maximum age was 66 years. This is comparable to other study conducted by Sen et al. in which mean age of subjects were $46.65 \pm 15.06$ years ${ }^{(12)}$ and Mahaling et al. had shown mean age as $49.14 \pm 9.65$ years ${ }^{(13)}$. The western communities' studies had shown mean age of subjects ranging from 41 - 45 years. In this study it is observed that our subjects were 5 - 10 years elder than the subjects studied elsewhere, this is because the largest groups of patient in our study were in the fifth and sixth decades.

Our study had showed statistically significant positive correlation of age with grades of NAFLD ( $p$ value 0.000). The steatosis grade was found to be increased with the advancement of age. This agrees with the results of Frith et al and Mahmoud et al who reported that NAFLD prevalence increases with advancement of age. ${ }^{(14,15)}$.

BMI of the participants varied from 22.5 to 42.1 $\mathrm{kg} / \mathrm{m}^{2}$ with mean value of $29.87 \pm 4.63 \mathrm{~kg} / \mathrm{m}^{2} .19 \%$ of the studied group had normal BMI, $31 \%$ were overweight and $50 \%$ were obese. This is comparable to other study conducted by Sen et al. in which mean BMI of subjects were $29.5 \pm 3.34 \mathrm{~kg} / \mathrm{m}^{2}{ }^{(12)}$ and Bhusal et al. had shown mean BMI as $27.97 \pm 4.28$ $\mathrm{kg} / \mathrm{m}^{2}{ }^{(10)}$. In our study no association was found between grades of NAFLD and BMI and sex. This agrees with the results of Sen et al ${ }^{\mathbf{( 1 2})}$.
Out of 100 subjects included in the study, grade I found to be the highest $51 \%$ followed by grade II $42 \%$ and grade III $7 \%$.

During the diagnosis, the majority of NAFLD patients were asymptomatic and the disease was discovered incidentally. $38 \%$ of the patients in this study were a symptomatic and this is comparable to Indian studies but much less than Western studies that have reported asymptomatic patients between $47.7 \%$ and $64 \%$.

Visceral obesity, dyslipidemia, type 2 diabetes mellitus and metabolic syndrome are the most important risk factors for NAFLD. Out of 100 patients in this study $37 \%$ had diabetes mellitus, $18 \%$ were hypertensive and 7\% were both diabetic and hypertensive.

We have observed alteration in LFT in the patients with NAFLD and the parameters which were altered are SGOT (AST) in $21 \%$ of patients and SGPT (ALT) in $17 \%$ of patients. This is consistent with the results obtained by Hegazy et al. who reported that patients with NAFLD had higher levels of ALT than subjects with healthy liver ${ }^{(\mathbf{1 6})}$. We have also observed that as the grade of NAFLD increased, there were associated significant enzyme elevations, increasing the probability of steatohepatitis.

The total cholesterol was elevated in $58 \%$ of the studied group (20\% is borderline high and $38 \%$ is high). TG was elevated in $61 \%$ of the studied group (25\% is borderline high and $36 \%$ is high). HDL decreased in $49 \%$ of the studied group. LDL was elevated in $49 \%$ of the studied group $(20 \%$ is borderline high and $13 \%$ is high and $16 \%$ is very high). VLDL was elevated in 39\% of the studied group. This is comparable to other study by Mahaling et al. which reported that the total cholesterol, TG, LDL and VLDL were elevated in $45.71 \%, 67.14 \%$, $34.28 \%$, and $25.71 \%$ respectively and HDL decreased in $62.85 \%{ }^{(13)}$ and Tanwani et al. in which total cholesterol, TG, LDL and VLDL were elevated in $62 \%, 50.7 \%, 39 \%, 39 \%$ respectively and HDL decreased in $51.7 \%{ }^{(11)}$.

Dyslipidemia was observed in $91 \%$ of participants. The mean value of the total cholesterol, TG, LDL, VLDL, HDL were 217.22 \pm 46.83 , $187,13 \pm 55.39, \quad 136.59 \pm 31.43, \quad 31.67 \pm 9.76$, $47.04 \pm 9.15$ respectively.

It was noted that as the grade of NAFLD increased, there were associated significant increase in levels of serum total cholesterol (P-value 0.005), TG (P-value 0.002), LDL (P-value 0.001) and VLDL (P-value 0.003) and associated significant decrease in HDL (P-value 0.001). This agrees with the results of Tanwani et al., Sen et al., Mahaling et al., and 
Mahmoud et al. ${ }^{(11,12,13,15)}$ and disagrees with Bhusal et al. ${ }^{(10)}$ because of the inability of Bhusal et al. to enroll participants from severe NAFLD category.

To summarize, ultrasound can be used as a primary tool for diagnosis of NAFLD. It is available and relatively inexpensive method that can detect various grades of NAFLD supported by increased lipid profile values.

Liver biopsy is the most accurate in diagnosis of NAFLD But it is clinically impractical because of the large numbers of patients with NAFLD and the high cost of liver biopsy and sampling errors ${ }^{(7)}$. Also it is a painful procedure with dangerous complication like bleeding ${ }^{(\boldsymbol{8})}$.

\section{CONCLUSION}

Dyslipidemia was found in most patients of NAFLD so both abdominal ultrasonography and increased lipid profile values can be used to detect NAFLD early.

\section{REFERENCES}

1. Younossi ZM, Koenig AB, Abdelatif D, Fazel Y, Henry L, Wymer M(2016): Global epidemiology of nonalcoholic fatty liver disease-Meta-analytic assessment of prevalence, incidence, and outcomes. Hepatology, 64:73-84.

2. Brunt EM (2007): Pathology of fatty liver disease. Mod. Pathol., 20(1): S40-S48.

3. Chalasani N, Younossi Z, Lavine JE, Charlton M, Cusi K, Rinella M, Harrison SA, Brunt EM et al. (2018): The diagnosis and management of non-alcoholic fatty liver disease: practice guidance from the American Association for the Study of Liver Diseases. Hepatology, http://dx.doi.org/10.1002/hep.29367 .

4. Sookoian S, Pirola CJ (2014): NAFLD: metabolic makeup of NASH: from fat and sugar to amino acids. Nat. Rev. Gastroenterol. Hepatol.,. 11(4): 205-207.

5. Lonardo A, Sookoian S, Chonchol M, Loria P, Targher G (2013): Cardiovascular and systemic risk in nonalcoholic fatty liver disease - atherosclerosis as a major player in the natural course of NAFLD. Curr. Pharm. Des., 19(29):5177-5192.
6. De Minicis S, Marzioni M, Saccomanno S, Rychlicki C, Agostinelli L, Trozzi L, Benedetti A, Svegliati-Baroni G (2012): Cellular and molecular mechanisms of hepatic fibrogenesis leading to liver cancer. Transl Gastrointest Cancer, 1: 88-94.

7. Shahin M, Rasoul S, Mehdi N, Masoumeh PH, Sadaf GS, Reza M, Masoud S (2012): Sampling error in histopathology findings of nonalcoholic fatty liver disease: a post mortem liver histology study. Arch Iran Med., 15: 418-421.

8. Figen CC, Nevil A, Hasan N (2010): Complications and efficiency of liver biopsies using the Tru-Cut biopsy gun. J Infect Dev Ctries., 4:91-95.

9. Chan $T$ and Wong $V$ (2016): $I n$ search of new biomarkers for nonalcoholic fatty liver disease. Clinical Liver Disease, 8: 19-23.

10. Bhusal KR, Simkhada R, Nepal $P$ (2017):Lipid profile in different grades of Ultrasonic Non-Alcoholic Fatty Liver Disease. JCMS Nepal., 13(2):258-61.

11. Tanwani,B. M., Jamali,A. A., Jamali, G. M., Jamali, A. A., and Sohail,M. M.(2018): Non Alcoholic Fatty Liver Disease: Assessment of Lipid Profile Estimation in Different Grades of Fatty Liver on Ultrasound. Open Journal o preventive medicine, 8, 70- 83.

12. Sen A, Kumar J, Misra R et al. (2013): Lipid Profile of Patients Having Non-Alcoholic Fatty Liver Disease as per Ultrasound Findings in North Indian Population: A Retrospective Observational Study. Journal of Medical and Allied Sciences, 3, 59-62.

13. Mahaling D and Basavaraj M (2013): Comparison of Lipid Profile in Differ-ent Grades of Non-Alcoholic Fatty Liver Disease Diagnosed on Ultrasound. Asian Pacific Journal of Tropical Biomedicine, 3:907-912.

14. Frith J, Day CP, Henderson E, Burt AD, Newton JL (2009): Non-alcoholic fatty liver disease in older people. Gerontology, 55(6):607-13.

15. Mahmoud H'S, Helal MM, Hassan MH, Sherif MF (2015): Correlation between Anthropometric Measures, Lipid Profile and Serum Adiponectin and Steatosis in Nondiabetic Nonalcoholic Fatty Liver Disease. British Journal of Medicine and Medical Research, 7(9):771-8.

16. Mona A, Hatem M, Dina F and Yasser H (2012): Liver ultrasound is more sensitive in assessing the severity of nonalcoholic fatty liver disease with homeostasis model assessment-insulin resistance. Egyptian Liver Journal, 2:41-46. 